\title{
Effects of Implanted Deuterium on In-Situ Irradiation Fatigue Behaviors of Cold-Worked 316 Stainless Steel at 60 and $300^{\circ} \mathrm{C}$
}

\author{
Yoshiharu Murase $^{1}$ and Norikazu Yamamoto ${ }^{1,2}$ \\ ${ }^{1}$ National Institute for Materials Science, Tsukuba 305-0047, Japan \\ ${ }^{2}$ Interdisciplinary Graduate School of Engineering Sciences, Kyushu University, Kasuga 816-8580, Japan
}

\begin{abstract}
Stress-controlled fatigue tests were performed for $20 \%$ cold-worked 316 stainless steel under in-situ $10 \mathrm{MeV}$ deuteron irradiation with an energy degrader at 60 and $300^{\circ} \mathrm{C}$. The irradiation dose rate and the deuterium implantation rate were arranged in response to beam intensity in three conditions as (A) $1.0 \times 10^{-7} \mathrm{dpa} / \mathrm{s}$ and $1.1 \times 10^{-3} \mathrm{appm} / \mathrm{s},(\mathrm{B}) 5.0 \times 10^{-7} \mathrm{dpa} / \mathrm{s}$ and $5.5 \times 10^{-3} \mathrm{appm} / \mathrm{s}$ and $(\mathrm{C}) 1.0 \times 10^{-6} \mathrm{dpa} / \mathrm{s}$ and $1.1 \times 10^{-2} \mathrm{appm} / \mathrm{s}$, respectively. The number of fatigue cycles to fracture $\left(N_{\mathrm{F}}\right)$ increased with the dose rate in order of conditions $(\mathrm{A}),(\mathrm{B})$ and (C) at $300^{\circ} \mathrm{C}$, while $N_{\mathrm{F}}$ was lower in condition (C) than that in condition (B) irrespective of the higher dose rate at $60^{\circ} \mathrm{C}$. Although transgranular cracking in the ductile fracture mode was indicated on fracture surface for all specimens, higher density of dimples was formed for the in-situ irradiation specimen in condition $(\mathrm{C})$ at $60^{\circ} \mathrm{C}$. Some evidence of effects of implanted deuterium on in-situ irradiation fatigue behavior were demonstrated in this paper. [doi:10.2320/matertrans.MBW201014]
\end{abstract}

(Received October 22, 2010; Accepted December 20, 2010; Published February 9, 2011)

Keywords: stainless steel, deuteron irradiation, fatigue, in-situ irradiation effect, hydrogen-related-fracture

\section{Introduction}

The in-situ irradiation effect on fatigue behavior is one of the key issues in evaluating the feasibility of nuclear reactor materials subjected to not only severe atomic displacement damage but also simultaneous periodic external loads. In the course of extensive efforts to accumulate available experimental data on in-situ irradiation fatigue tests, ${ }^{1-3)}$ the mechanism of in-situ irradiation effect on fatigue behavior has been proposed in terms of the interaction between radiation-induced defect (RID) clusters and moving dislocations. In addition to these two factors of in-situ irradiation and fatigue loading, structural materials are also exposed to hydrogen isotopes due to nuclear transmutation and permeation from light-water coolants in the reactor core environment. Although the important role of hydrogen in irradiated assisted corrosion cracking (IASCC) has been suggested in some literature, ${ }^{4,5)}$ the effects of hydrogen isotopes on material behaviors under in-situ irradiation have been little examined due to some technological difficulties to establish in-situ irradiation testing facilities.

In the present study, $10 \mathrm{MeV}$ deuteron irradiation is adopted to produce the displacement damage and hydrogen isotopes in a small specimen. Stress-controlled fatigue tests were conducted for $20 \%$ cold-worked 316 stainless steel under in-situ $10 \mathrm{MeV}$ deuteron irradiation with the energy degrader at 60 and $300^{\circ} \mathrm{C}$. The objective of the present work was to investigate the effects of implanted deuterium on in-situ irradiation fatigue behavior at these temperatures.

\section{Experimental}

The material used in the present study was a commercial SUS316 stainless steel. Its composition is 7.82 mass\% Cr, 1.98 mass\% W, and Mo, Mn, V, Ta, Ni, Si and C below $1 \mathrm{mass} \%$ in sum total and Fe for the balance. The annealed sheets of the alloy with the grain controlled to $8 \mu \mathrm{m}$ in diameter were rolled to $20 \%$ reduction in thickness to produce the cold-work sheets. The cold-worked sheet of $90 \mu \mathrm{m}$ in thickness was punched out into the specimen type shown in Fig. 1. A fatigue starter side-notch was introduced into the gauge of the specimen by means of spark erosion, as presented in Fig. 1. Fatigue loading mode was tensiontension in stress control under a constant loading rate of $50 \mathrm{MPa} / \mathrm{s}$ with $416.9 \leftrightarrow 183.6 \mathrm{MPa}$ and $381.6 \leftrightarrow 167.9 \mathrm{MPa}$ at 60 and $300^{\circ} \mathrm{C}$, respectively. In the present $10 \mathrm{MeV}$ deuteron irradiation, an energy degrader was used to maximize and homogenize the rate of deuterium implantation into the $90 \mu \mathrm{m}$-thick-specimen. In response to beam intensity, the irradiation dose rate $\left(R_{\text {dpa }}\right)$ and the deuterium implantation rate $\left(R_{\text {imp }}\right)$ were arranged in three conditions; $(\mathrm{A})$ $1.0 \times 10^{-7} \mathrm{dpa} / \mathrm{s}$ and $1.1 \times 10^{-3} \mathrm{appm} / \mathrm{s}$, (B) $5.0 \times 10^{-7}$ $\mathrm{dpa} / \mathrm{s}$ and $5.5 \times 10^{-3} \mathrm{appm} / \mathrm{s}$ and (C) $1.0 \times 10^{-6} \mathrm{dpa} / \mathrm{s}$ and $1.1 \times 10^{-2} \mathrm{appm} / \mathrm{s}$, respectively. The ratio of $R_{\mathrm{imp}}$ to $R_{\mathrm{dpa}}$ was a constant of $1.1 \times 10^{4} \mathrm{appm} / \mathrm{dpa}$ for all irradiation conditions. Figure 2 shows the damage and implantation profiles with depth $\left(D_{\mathrm{p}}\right)$ from the irradiated surface in condition (C) calculated by SRIM 2006 code. The specimen was cooled by circulating helium gas in order to compensate for beam heating. The specimen temperature was controlled at $60 \pm 3^{\circ} \mathrm{C}$ and $300 \pm 5^{\circ} \mathrm{C}$ by adjusting the output of the helium gas heater during the fatigue tests. Experimental details of the in-situ irradiation fatigue testing machine are described elsewhere. ${ }^{1)}$

During the fatigue tests, the relative displacement of specimen gauge $(\Delta d)$ was plotted as a function of the number of fatigue cycles $(N)$ for all the fatigue tests. The relative displacement is the difference of the actual displacement at the upper stress between the $N$ th cycle and the first cycle. The scattering of the number of cycles to fracture $\left(N_{\mathrm{F}}\right)$ is estimated to be within $\pm 15 \%$ as a result of numerous function tests for fatigue specimens shown in Fig. 1. After the fatigue tests, the fracture surface was examined by a scanning electron microscope (SEM, JSM-5310) for all specimens. Tensile tests were also performed at 60 and $300^{\circ} \mathrm{C}$ for the irradiated specimens without a side-notch at the respective 


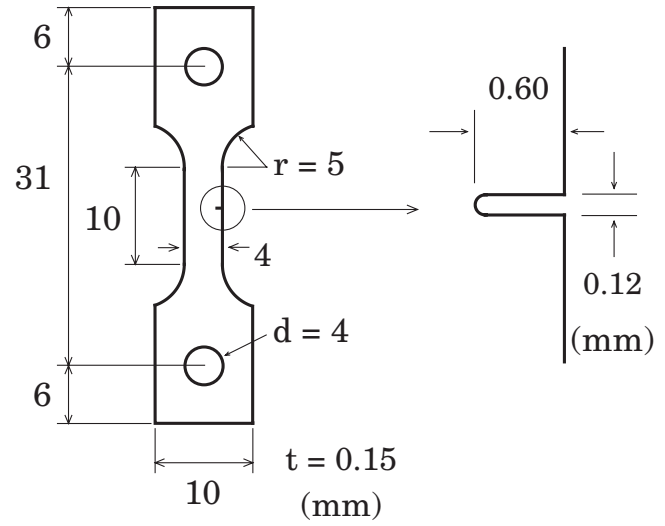

Fig. 1 Dimensions of specimen for fatigue test.

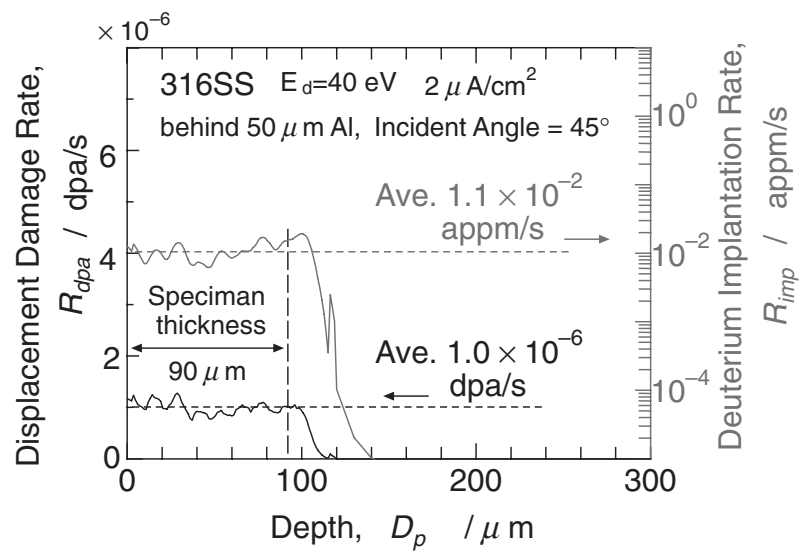

Fig. 2 The damage and implantation profile calculated by SRIM 2006 code in irradiation condition $(\mathrm{C})$.

temperature. The changes in tensile properties were measured from the pre-irradiation dose levels, ranging up to 0.138 dpa.

Although the measurement of thermal desorption spectroscopy (TDS) could not be performed for the irradiated specimen in the present experiments, the equilibrium deuterium concentration in specimen under irradiation at steady state was roughly estimated by a simple diffusion equation. Figure 3 shows the schematic deuterium concentration in the specimen. A simple diffusion equation is described as below,

$$
\mathrm{d} u / \mathrm{d} t=D \times \mathrm{d}^{2} u / \mathrm{d} x^{2}+J_{0}
$$

where $u(x, t), D$ and $J_{0}$ are deuterium concentration $\left(\mathrm{m}^{-3}\right)$, deuterium diffusivity $\left(\mathrm{m}^{2} / \mathrm{s}\right)$ and deuterium implantation rate $\left(\mathrm{m}^{-3} / \mathrm{s}\right)$, respectively. At steady state, $\mathrm{d} u / \mathrm{d} t=0$, a solution of eq. (1) is represented as

$$
u(x)=J_{0} / 2 D \times(l-x) x+u_{0}
$$

In eq. (2), $l$ and $u_{0}$ are specimen thickness $(90 \mu \mathrm{m})$ and deuterium concentration at the specimen surfaces $(x=0, l)$, respectively. When the deuterium recombination coefficient, $K_{0}\left(\mathrm{~m}^{4} / \mathrm{s}\right)$, is assumed to be similar at both surfaces, boundary condition at specimen surface for the solution is

$$
\phi / 2=K_{0} \times u_{0}^{2}
$$

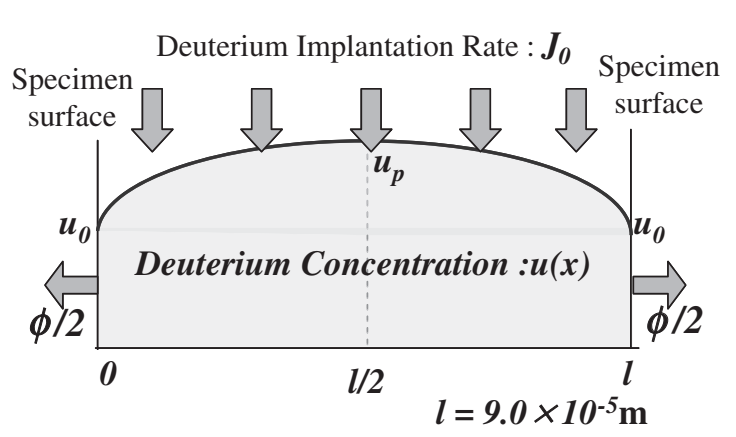

Fig. 3 Schematic deuterium concentration profile in simple diffusion model.

\begin{tabular}{|c|c|c|c|}
\hline Temperature & Irrad. Cond. & $u_{0}(\mathrm{appm})$ & $u_{\mathrm{p}}(\mathrm{appm})$ \\
\hline \multirow{3}{*}{$60^{\circ} \mathrm{C}$} & A & 3.0 & $1.5 \times 10^{2}$ \\
\hline & $\mathrm{B}$ & 6.6 & $7.2 \times 10^{2}$ \\
\hline & $\mathrm{C}$ & 9.4 & $1.4 \times 10^{3}$ \\
\hline \multirow{3}{*}{$300^{\circ} \mathrm{C}$} & A & 1.7 & 2.0 \\
\hline & $\mathrm{B}$ & 3.9 & 5.1 \\
\hline & $\mathrm{C}$ & 5.5 & 7.9 \\
\hline
\end{tabular}

Table 1 The estimated value of equilibrium deuterium concentration at $60^{\circ} \mathrm{C}$ and $300^{\circ} \mathrm{C}$

where $\phi$ is the equilibrium deuterium flux $\left(=J_{0} \times l\right)$. The value of $\phi$ is $8.42 \times 10^{16}\left(\mathrm{~m}^{-2} / \mathrm{s}\right)$ in irradiation condition $(\mathrm{C})$ in the present experiment. The concentration $u(x)$ at steady state is derived from eqs. (2) and (3) in applying the experimental results of $D$ and $K_{0}$ at $T(\mathrm{~K})$ for 304 stainless steel $^{6)}$ expressed as

$$
D\left(\mathrm{~m}^{2} / \mathrm{s}\right)=3.5 \times 10^{-8} \exp \left(-Q_{\mathrm{D}} / R T\right)
$$

and

$$
K_{0}\left(\mathrm{~m}^{4} / \mathrm{s}\right)=8.3 \times 10^{-31} \exp (-E / R T)
$$

where $Q_{\mathrm{D}}(=42400 \mathrm{~J} / \mathrm{mol})$ and $E(=7000 \mathrm{~J} / \mathrm{mol})$ are activation energies of diffusion and recombination coefficients, respectively. Table 1 presents the estimated values of equilibrium deuterium concentration (appm), $u_{0}(x=0)$ and $u_{\mathrm{p}}(x=l / 2)$, in irradiation conditions (A), (B) and (C) at 60 and $300^{\circ} \mathrm{C}$. Some upward revision of deuterium concentration could be expected at $60^{\circ} \mathrm{C}$ when the effect of deuterium trap at RID clusters is considered in the simple diffusion model. Although the present estimation only provides tentative values due to adoption of $D$ and $K_{0}$ for different material (304 stainless steel) as well as disregard of deuterium trap, a significant difference of deuterium concentration between 60 and $300^{\circ} \mathrm{C}$ was indicated in each irradiation condition.

\section{Results}

Figure 4 shows the plots of $(\Delta d)$ as a function of $N$ for the unirradiated, in-situ irradiation specimens at (a) 60 and (b) $300^{\circ} \mathrm{C}$. The number of cycles to fracture $\left(N_{\mathrm{F}}\right)$ was larger under in-situ irradiation conditions than that in unirradiated condition at both 60 and $300^{\circ} \mathrm{C}$. The extension of $N_{\mathrm{F}}$ under 


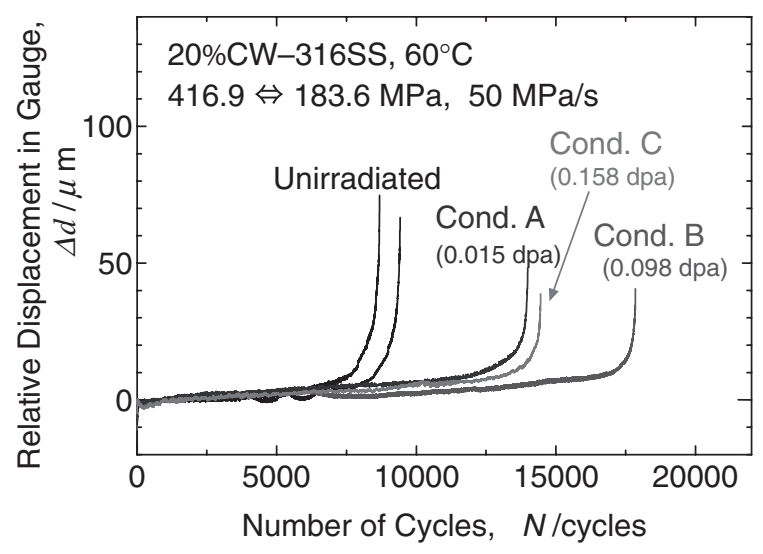

(a) $60{ }^{\circ} \mathrm{C}$

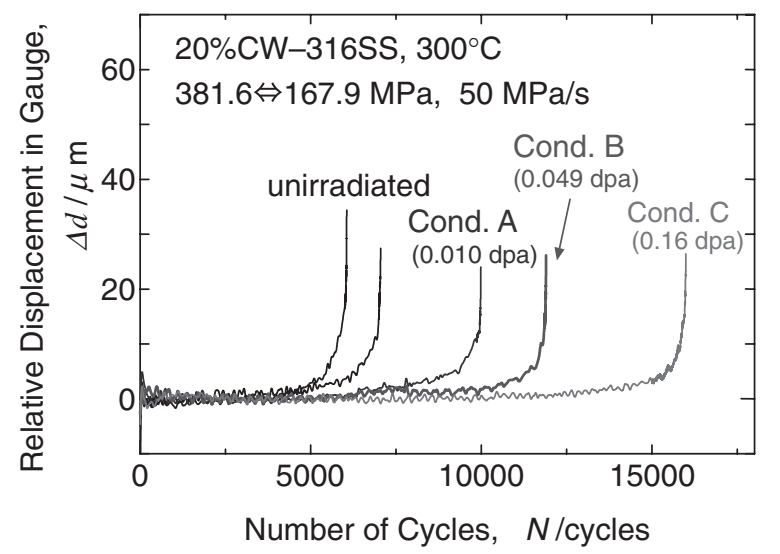

(b) $300{ }^{\circ} \mathrm{C}$

Fig. 4 Relative displacement in specimen gauge as a function of the number of cycles for unirradiated and in-situ irradiation specimens at (a) $60^{\circ} \mathrm{C}$ and (b) $300^{\circ} \mathrm{C}$.

in-situ irradiation increased in order of conditions (A), (B) and (C) at $300^{\circ} \mathrm{C}$ (see Fig. 4(b)), while in order of (A), (C) and (B) at $60^{\circ} \mathrm{C}$ (see Fig. 4(a)). Thus, the extension of $N_{\mathrm{F}}$ was enhanced with irradiation dose rate at $300^{\circ} \mathrm{C}$, whereas not in that manner at $60^{\circ} \mathrm{C}$. The changes in tensile stresses with dose level are shown in Table 2. The increase of ultimate tensile stress $(\triangle U T S)$ and $0.2 \%$ offset yield stress $(\Delta 0.2 \%$ $Y S$ ) was $270 \mathrm{MPa}$ and $230 \mathrm{MPa}$ at $0.138 \mathrm{dpa}$ and $60^{\circ} \mathrm{C}$, similarly $170 \mathrm{MPa}$ and $115 \mathrm{MPa}$ at $0.137 \mathrm{dpa}$ and $300^{\circ} \mathrm{C}$ respectively. This indicates that irradiation hardening is induced by introduction of RID clusters for specimens during in-situ irradiation fatigue tests at both 60 and $300^{\circ} \mathrm{C}$. After the fatigue tests, the fracture surface was examined by SEM for all specimens. The fractographic morphology of fracture surface was quite similar for all specimens and characterized by glide plane decohensions, fatigue striations and dimples, with an indication of transgranular cracking in the ductile fracture mode. However, for the in-situ irradiation specimen in condition (C) at $60^{\circ} \mathrm{C}$, a higher density of dimples was detected on the fracture surface. The SEM photos of typical fracture surface for unirradiated and in-situ irradiation specimens in condition (C) are shown in Fig. 5 at (a) $60^{\circ} \mathrm{C}$ and (b) $300^{\circ} \mathrm{C}$. Figure 6 presents the plotting of striation spacing $\left(s_{\mathrm{p}}\right)$ as a function of the distance from the notch tip $\left(d_{\mathrm{n}}\right)$ for each specimen at (a) $60^{\circ} \mathrm{C}$ and (b) $300^{\circ} \mathrm{C}$. Since
Table 2 The changes in tensile stresses with dose level at $60^{\circ} \mathrm{C}$ and $300^{\circ} \mathrm{C}$.

\begin{tabular}{cccc}
\hline Temperature & $\begin{array}{c}\text { Dose level } \\
(\mathrm{dpa})\end{array}$ & $\begin{array}{c}0.2 \% \text { Yield Stress } \\
(\mathrm{MPa})\end{array}$ & $\begin{array}{c}\text { Tensile Strength } \\
(\mathrm{MPa})\end{array}$ \\
\hline \multirow{3}{*}{$60^{\circ} \mathrm{C}$} & 0 & 690 & 800 \\
\cline { 2 - 4 } & 0.0306 & 820 & 960 \\
\cline { 2 - 4 } & 0.0612 & 905 & 1025 \\
\hline \multirow{3}{*}{$300^{\circ} \mathrm{C}$} & 0.1380 & 960 & 1030 \\
& 0 & 590 & 695 \\
\cline { 2 - 4 } & 0.0513 & 760 & 820 \\
\hline
\end{tabular}

Table 3 Number of cycles for fatigue process in each irradiation condition at $60^{\circ} \mathrm{C}$ and $300^{\circ} \mathrm{C}$

\begin{tabular}{ccccc}
\hline Temperature & Irrad. Cond. & $N_{\mathrm{F}}$ & $N_{\mathrm{c}}$ & $N_{\mathrm{i}}$ \\
\hline \multirow{3}{*}{$60^{\circ} \mathrm{C}$} & unirradiated & 9419 & 4866 & 4553 \\
\cline { 2 - 5 } & $\mathrm{A}$ & 13864 & 5809 & 8055 \\
\cline { 2 - 5 } & $\mathrm{B}$ & 17849 & 6581 & 11268 \\
\hline \multirow{3}{*}{$300^{\circ} \mathrm{C}$} & $\mathrm{C}$ & 14452 & 5240 & 9212 \\
& unirradiated & 6054 & 2561 & 3493 \\
\cline { 2 - 5 } & $\mathrm{A}$ & 9983 & 3963 & 6020 \\
\cline { 2 - 5 } & $\mathrm{B}$ & 11896 & 4798 & 7098 \\
\hline
\end{tabular}

striation spacing was too small to be resolved by SEM in the vicinity of the notch tip, the measurement was conducted in the area between the distance starting at $60 \mu \mathrm{m}$ from the notch tip up to the unstable ductile fracture point. This area is designated as the striation area in the present paper. Striation analysis $^{2,3)}$ was conducted to calculate the number of fatigue cycles in the striation area (denoted as $N_{\mathrm{c}}$ ) for all specimens. The difference between $N_{\mathrm{F}}$ and $N_{\mathrm{c}}$ is denoted as $N_{\mathrm{i}}$, corresponding to the number of cycles for crack initiation and growth until $60 \mu \mathrm{m}$ in length. Table 3 presents $N_{\mathrm{F}}, N_{\mathrm{c}}$ and $N_{\mathrm{i}}$ for all specimens. These results indicate that the extension of $N_{\mathrm{F}}$ was attributed to the increases in both $N_{\mathrm{c}}$ and $N_{\mathrm{i}}$ under in-situ irradiation conditions. The increase of $N_{\mathrm{C}}$ and $N_{\mathrm{i}}$ with irradiation dose rate was quite similar in its inclination to that of $N_{\mathrm{F}}$, namely in order of conditions (A), (B) and (C) at $300^{\circ} \mathrm{C}$, whereas in order of (A), (C) and (B) at $60^{\circ} \mathrm{C}$.

\section{Discussion}

Fatigue behaviors of $20 \%$ cold-worked 316 stainless steel under in-situ $17 \mathrm{MeV}$ proton irradiation at 60 and $300^{\circ} \mathrm{C}$ have been investigated in previous papers. ${ }^{2,3)}$ Striation analyses have revealed the prolonged fatigue processes of crack initiation and propagation under in-situ irradiation at both temperatures. It is well recognized that the development of inhomogeneous dislocation structures such as cells and wallchannels is closely related to the progress of fatigue processes in ductile fracture mode. Since the radiation-induced defect (RID) clusters can act as obstacles for mobile dislocations, the continuous introduction of RID clusters under in-situ irradiation would severely impede the rearrangement of dislocation structures. Therefore, the effect of in-situ irradi- 

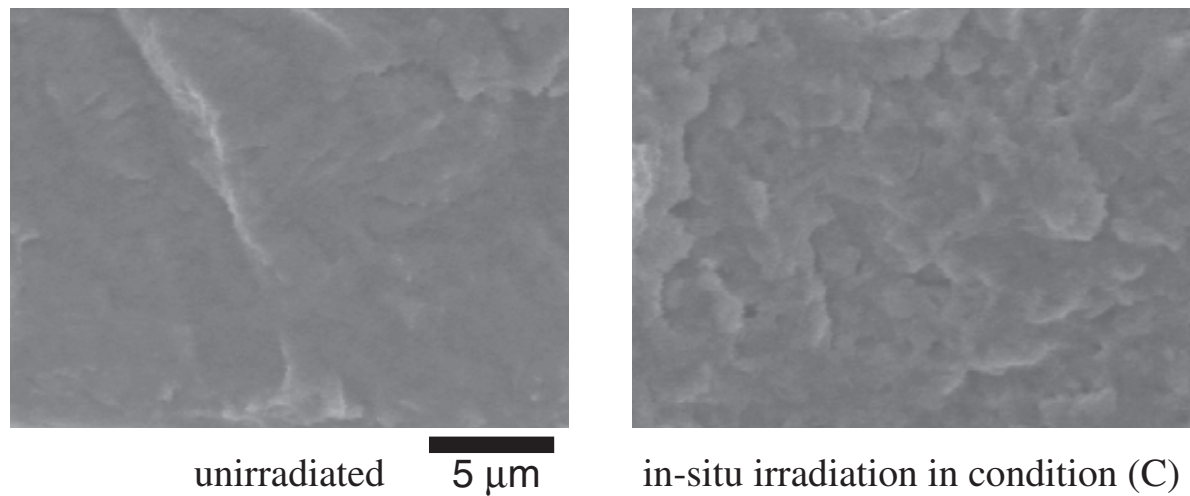

(a) $60{ }^{\circ} \mathrm{C}$

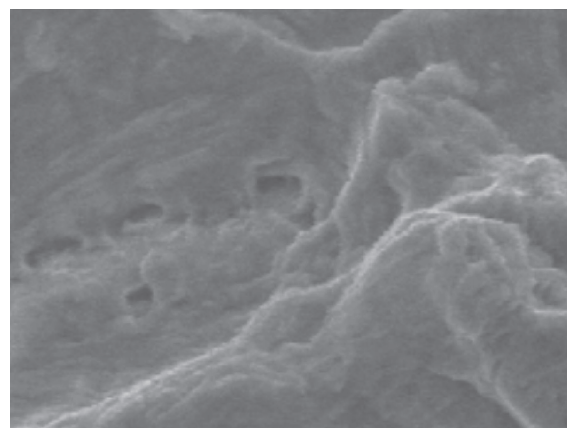

unirradiated

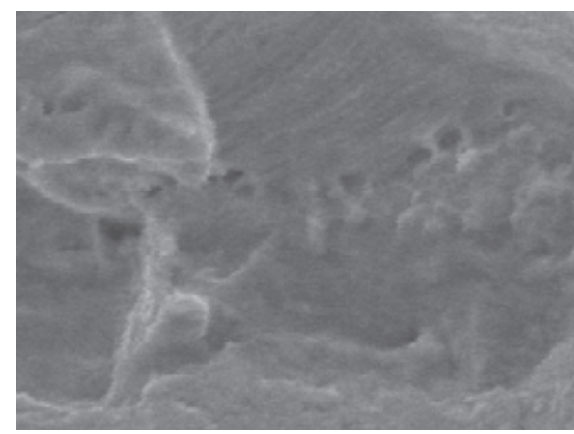

in-situ irradiation in condition (C)

(b) $300{ }^{\circ} \mathrm{C}$

Fig. 5 SEM photos of typical fracture surface for the unirradiated and in-situ irradiation specimens in condition (C) at (a) $60^{\circ} \mathrm{C}$ and (b) $300^{\circ} \mathrm{C}$.

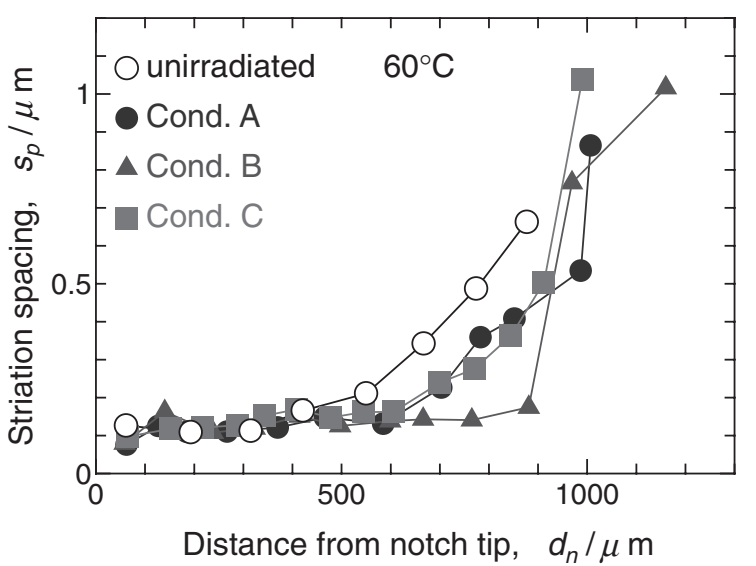

(a) $60{ }^{\circ} \mathrm{C}$

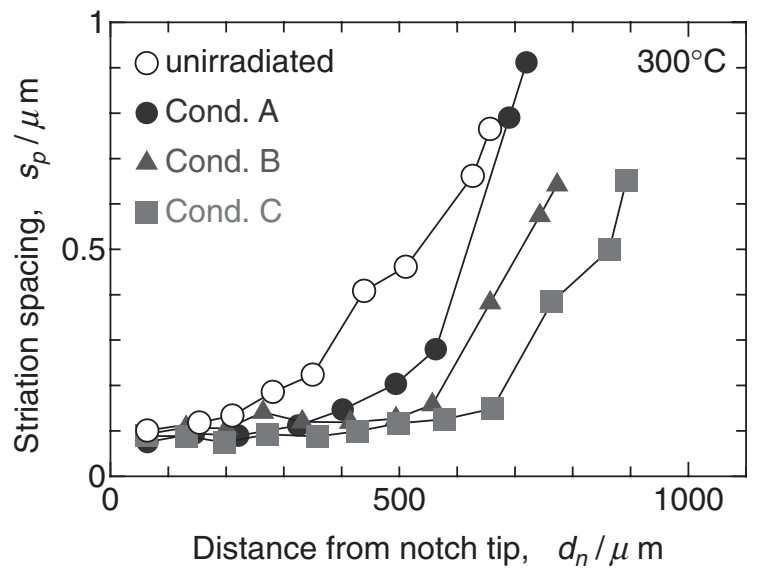

(b) $300{ }^{\circ} \mathrm{C}$

Fig. 6 Plots of striation spacing with distance from notch tip for the unirradiated and in-situ irradiation specimens at (a) $60^{\circ} \mathrm{C}$ and (b) $300^{\circ} \mathrm{C}$.

ation on fatigue behavior has been explained in terms of the interaction between RID clusters and moving dislocations. ${ }^{2,3)}$ On the other hand, the effect of hydrogen on the interaction between dislocations in $310 \mathrm{~S}$ stainless steel has been examined during in-situ deformation experiments by transmission electron microscope (TEM). ${ }^{7)}$ It has been directly demonstrated that solute hydrogen reduced the elastic interaction between dislocations, thereby enhancing the mobility of dislocations. Another aspect of hydrogen effect in ductile fracture of steels has been pointed out on the basis of the hydrogen-enhanced strain-induced vacancy model. ${ }^{8,9)}$ Enhanced formation of strain-induced vacancies due to interaction with hydrogen promotes their agglomeration, leading to nucleation of a high density of micro-voids at the cross slips of dislocations in the vicinity of the crack tip. Therefore, the presence of hydrogen can induce the localization of unstable dimple fractures, leading to rapid crack propagation. 
In the present experiments, the number of cycles to fracture $\left(N_{\mathrm{F}}\right)$ was larger under in-situ irradiation conditions than that in unirradiated condition at both 60 and $300^{\circ} \mathrm{C}$, as shown in Fig. 4. Table 2 data suggest irradiation hardening, which is induced by introduction of RID clusters for specimens during in-situ irradiation fatigue tests at both 60 and $300^{\circ} \mathrm{C}$. Striation analysis reveals that the extension of $N_{\mathrm{F}}$ was attributed to the increases in both $N_{\mathrm{C}}$ and $N_{\mathrm{i}}$ under in-situ irradiation conditions (see Table 3). Furthermore, the transgranular cracking in the ductile fracture mode was indicated by SEM observation on fracture surface for all specimens. These results strongly suggest that the extension of $N_{\mathrm{F}}$ under in-situ irradiation can be explained by the in-situ irradiation effect based on the interaction between RID clusters and moving dislocations. At $300^{\circ} \mathrm{C}$, the increase of $N_{\mathrm{F}}$ as well as $N_{\mathrm{C}}$ and $N_{\mathrm{i}}$ with irradiation dose rate is shown in Table 3. Because continuous introduction of RID clusters is proportionally enhanced with dose rate, the increase of dose rate would simply reflect the increase of in-situ irradiation effect at this temperature. However, at $60^{\circ} \mathrm{C}$, Table 3 shows lower $N_{\mathrm{F}}$ as well as $N_{\mathrm{C}}$ and $N_{\mathrm{i}}$ in irradiation condition (C) than those in (B) irrespective of the higher dose rate. Furthermore, the higher density of dimples on fracture surface was detected in irradiation condition (C) at $60^{\circ} \mathrm{C}$ (see Fig. 5(a)). Rough estimation of deuterium concentration during in-situ irradiation indicated a significant increase of deuterium concentration at $60^{\circ} \mathrm{C}$ in particular in condition (C), as shown in Table 1. Therefore, when a large amount of deuterium is existent in the material, the implanted deuterium can play a role in reducing the effect of in-situ irradiation on fatigue behavior.

Although a relative comparison of experimental results between different irradiation conditions has brought the presence of deuterium effect in condition (C) at $60^{\circ} \mathrm{C}$ into sharp relief, the evidence of deuterium effect in other irradiation conditions could not be detected in the present experiments. Since the balance of effects between in-situ irradiation and implanted deuterium would reflect fatigue behavior, the effect of deuterium can be covered by the effect of in-situ irradiation in the present comparative experimental methods. More extensive experiments of in-situ irradiation fatigue with precise arrangement of separate parameters between irradiation dose rate and deuterium implantation rate are definitely needed to clarify the threshold concentration of deuterium effects on fatigue behavior under in-situ irradiation.

\section{Conclusions}

Stress-controlled fatigue tests were performed for $20 \%$ cold-worked 316 stainless steel under in-situ $10 \mathrm{MeV}$ deuteron irradiation with an energy degrader at 60 and $300^{\circ} \mathrm{C}$. The irradiation dose rate was arranged in three conditions as (A) $1.0 \times 10^{-7} \mathrm{dpa} / \mathrm{s}$, (B) $5.0 \times 10^{-7} \mathrm{dpa} / \mathrm{s}$ and (C) $1.0 \times 10^{-6} \mathrm{dpa} / \mathrm{s}$ under a constant deuterium implantation ratio of $1.1 \times 10^{4} \mathrm{appm} / \mathrm{dpa}$. From the experimental results, the following conclusions can be drawn:

(1) The number of cycles to fracture $\left(N_{\mathrm{F}}\right)$ was larger under in-situ irradiation conditions than that in unirradiated condition at both 60 and $300^{\circ} \mathrm{C}$. The extension of $N_{\mathrm{F}}$ increased with irradiation dose rate at $300^{\circ} \mathrm{C}$, while not in that manner at $60^{\circ} \mathrm{C}$.

(2) Transgranular cracking in the ductile fracture mode was indicated by SEM observation on fracture surface for all specimens. Higher density of dimples was detected on fracture surface of the in-situ irradiation specimens in condition (C) at $60^{\circ} \mathrm{C}$.

(3) The extension of $N_{\mathrm{F}}$ under in-situ irradiation can be explained by the in-situ irradiation effect based on the interaction between RID clusters and moving dislocations. Because continuous introduction of RID clusters is proportionally enhanced with irradiation dose rate, the increase of dose rate would simply reflect the increase of in-situ irradiation effect at $300^{\circ} \mathrm{C}$.

(4) Rough estimation of deuterium concentration during in-situ irradiation indicated a significant increase of deuterium concentration at $60^{\circ} \mathrm{C}$ in particular in condition (C). When a large amount of deuterium is existent in the material, the implanted deuterium can play a role in reducing the effect of in-situ irradiation on fatigue behavior.

\section{Acknowledgement}

This work was financially supported by the Budget for Nuclear Research of the Ministry of Education, Culture, Sports, Science and Technology, based on the screening and counseling by the Atomic Energy Commission, and supported by Grant-in-Aid for Scientific Research (C) 22560830 .

\section{REFERENCES}

1) Y. Murase, J. Nagakawa, N. Yamamoto and Y. Fukuzawa: Creepfatigue response of $20 \% \mathrm{CW} 316 \mathrm{SS}$ under irradiation at $60^{\circ} \mathrm{C}$, (ASTM STP 1366, ASTM, West Conshohocken, 2000) pp. 713-724.

2) Y. Murase, J. Nagakawa and N. Yamamoto: J. Nucl. Mater. 302 (2002) 211-216.

3) Y. Murase, J. Nagakawa and N. Yamamoto: Fusion Engin. Design 81 (2006) 999-1003.

4) K. Fukuya, M. Nakano, K. Fujii and T. Torimaru: J. Nucl. Sci. Technol. 41 (2004) 673-681.

5) G. Furutani, N. Nakajima, T. Konishi and M. Kodama: J. Nucl. Mater. 288 (2001) 179-186.

6) M. Takizawa, K. Kikuchi, M. Okamoto and Y. Fujii: J. Nucl. Mater. 248 (1997) 15-18.

7) P. J. Ferreira, I. M. Robertson and H. K. Birnbaum: Acta Mater. 46 (1998) 1749-1757.

8) K. Takai, H. Shoda, H. Suzuki and M. Nagumo: Acta Mater. 56 (2008) 5158-5167.

9) M. Nagumo: Mater. Sci. Technol. 20 (2004) 940-950. 